\title{
Longitudinally extensive transverse myelopathy in a patient with CADASIL
}

\author{
Mielopatia transversa longitudinalmente extensa em um paciente com CADASIL \\ Wladimir Bocca Vieira de Rezende Pinto, Paulo Victor Sgobbi de Souza, Acary Souza Bulle Oliveira
}

A 52-year-old Brazilian man presented with a 3-year-history of progressive cognitive decline, seizures and tetraparesis with sphincter disturbances. Familial history was positive for stroke-like episodes. Examination disclosed spastic tetraparesis with posterior cord syndrome. Neuroimaging revealed a longitudinally extensive centromedullary hyperintensity in the spinal cord between C2-T1 levels and a diffuse leukoencephalopathy
(Figure), highly suggestive of Cerebral Autosomal Dominant Arteriopathy with Subcortical Infarcts and Leukoencephalopathy (CADASIL).

CADASIL is a common hereditary vasculopathy in adults characterized by chronic migraine, subcortical infarcts and cognitive and behavioral disturbances ${ }^{1,2}$. Spinal cord involvement is extremely rare, making this a differential diagnosis of demyelinating diseases ${ }^{2,3}$.
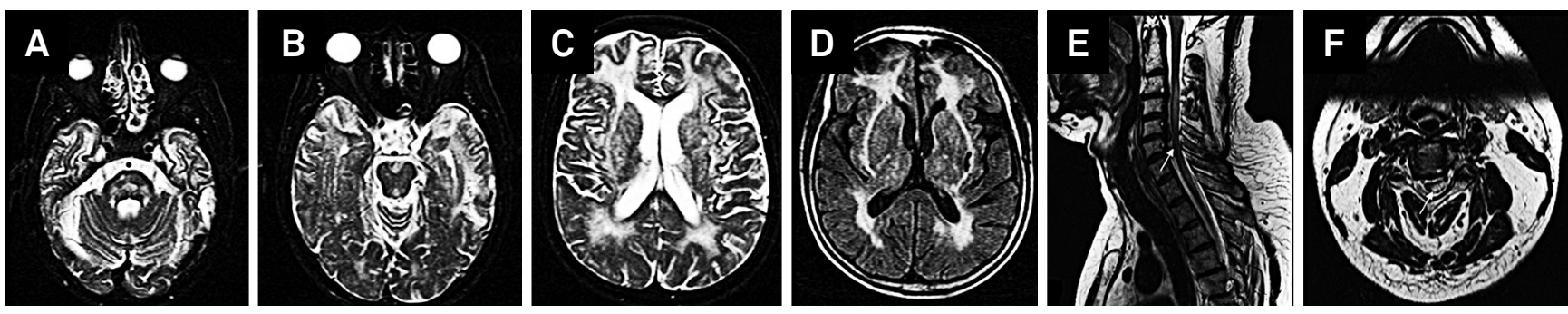

Axial T2-weighted brain MR images (A-C) and FLAIR image (D) disclosing diffuse hyperintense signal changes in the white matter, involving the external capsule, anterior temporal lobes and pons. (E-F) T2-weighted spine MRI disclosing longitudinally extensive signal change in the cervical spinal cord level (white arrow).

Figure. Spinal cord involvement in CADASIL.

\section{References}

1. Andre C. CADASIL: pathogenesis, clinical and radiological findings and treatment. Arq Neuropsiquiatr. 2010;68(2):287-99. doi:10.1590/S0004-282X2010000200026

2. Hinze S, Goonasekera M, Nannucci S, Quaqhebeur G, Briley D, Markus HS et al. Longitudinally extensive spinal cord infarction in CADASIL. Pract Neurol. 2015;15(1):60-2. doi:10.1136/practneurol-2014-000870
3. Bentley P, Wang T, Malik O, Nicholas R, Ban M, Sawcer S et al. CADASIL with cord involvement associated with a novel and atypical NOTCH3 mutation. J Neurol Neurosurg Psychiatry. 2011;82(8):855-60. doi:10.1136/jnnp.2010.223297

Universidade Federal de São Paulo, Divisão de Doenças Neuromusculares, Departamento de Neurologia e Neurocirurgia, Sao Paulo SP, Brazil. Correspondence: Wladimir Bocca Vieira de Rezende Pinto; UNIFESP, Departamento de Neurologia e Neurocirurgia; Rua Estado de Israel, 899 ; 04022-002 São Paulo SP, Brasil; E-mail: wladimirbvrpinto@gmail.com

Conflict of interest: There is no conflict of interest.

Received 25 January 2015; Received in final form 08 April 2015; Accepted 28 April 2015. 